Argentina, seguido por México). No obstante, estos detalles no desmerecen la calidad del libro que constituye una contribución ineludible al estudio de la historia del cine tanto para estudiosos como neófitos.

Aldona Bialowas Pobutsky

Oakland University

\title{
MARVIN A. LEWIS. Equatorial Guinean Literature in its National and Transnational
}

Contexts. Missouri: University of Missouri Press, 2017. 256 pp. ISBN 978-08262-2120-9.

En estos tiempos en que una mirada geo-cartográfica sobre las expresiones culturales parece que ha dejado de tener el menor sentido, Equatorial Guinean Literature in its National and Transnational Contexts, del profesor Marvin A. Lewis, viene a resituar la literatura de Guinea Ecuatorial. Lo que, en este caso, se hacía absolutamente necesario. A colocarla (o, mejor, a dislocarla) como el producto cultural tridimensional que es (africano, español y americano), en una perspectiva transnacional y transfronteriza. Haciéndole así superar el lugar marginal, menor y eternamente emergente, que dentro de las letras hispánicas tradicionalmente se le ha dado. Y esta tarea de contextualización de la literatura guineoecuatoriana es lograda por el autor a través de un serio y sesudo análisis de diferentes obras, de todos los géneros, del período 2007-2013. Lo que es de alabar, ya que la teoría nace y está iluminada por las obras, que son al fin y al cabo las "protagonistas" en la literatura, quedando salpicada de numerosísimos ejemplos, que la fortalecen y avalan.

Además, las obras escogidas no solo tienen estilos diferentes-de hecho, sus autores pertenecen a distintas generaciones-, sino que las experiencias vitales de estos son también muy dispares (exiliados, migrantes, no migrantes, retornados), dando cuenta de esa encrucijada que supone el encuentro - muchas veces choque- de lo nacional y lo diaspórico, del hogar y lo exterior (y hasta del no-lugar), de tradición y modernidad, etc. y que precisamente viene a espejear esa triple raíz, esa condición multicultural-más allá ser una nación multiétnica- de la literatura guineoecuatoriana que apuntábamos

\begin{tabular}{l}
111 \\
\hline ISSN 0034-9631 (Impreso)
\end{tabular} 
antes. La dura realidad del país, no solo durante la colonización, también tras la independencia en 1968, ha terminado produciendo que el lugar de creación de estos textos no sea un punto geográfico concreto, sino precisamente aquel lugar desde donde sus autores pueden escribir su país (España y Estados Unidos especialmente), lo que ha propiciado una mayor apertura a distintas teorías y propuestas estéticas, un más rico acercamiento y diálogo con otros textos, de lo que nacen nuevos temas y técnicas... y todo esto, sin renunciar a su pasado, a su tradición.

Lewis, aparte de una introducción donde expone los objetivos de su obra y un apartado de conclusiones, estructura su estudio del período 2007-2013 de la literatura guineoecuatoriana en siete capítulos. En el primero analiza precisamente el carácter transnacional de la literatura de Guinea Ecuatorial, a partir de la lectura de El metro, de Donato Ndongo, El porteador de Marlow: canción negra sin color, de César Mbá, y Autorretrato de un infiel, de José Siale, todas de 2007, cuyo análisis le permite observar las tensiones que surgen de las experiencias transnacionales y diaspóricas, desde el tratamiento de diferentes temas y con distintas visiones.

En el capítulo dos se centra en Malabo, capital guineoecuatoriana, como ciudad cultural indispensable para entender la expresión cultural de los no migrantes, ya que es el centro de la migración interna y de la modernización del país, tal como recogen las obras Ecos de Malabo (2009), de Maximiliano Nkogo, y Luz en la noche: poesía y teatro (2010), de Recadero Silabo, ambos no migrantes, por lo que pueden ofrecer el ethos del país, matizado por la ironía, el sarcasmo y la parodia.

Ya en el apartado tercero, Lewis estudia la escritura de mujeres, que sitúa en la tensión entre tradición y modernidad, a través de las novelas Las tres vírgenes de Santo Tomás (2008) y Tres almas para un corazón (2011), de Guillermina Mekuy, y Mokámbo: aromas de libertad (2010), de Victoria Evita Ika, en las que tratan temas como la poligamia, el fanatismo religioso o la migración interior.

En el capítulo cuarto, titulado De la ficción a la realidad, y a partir de En el lapso de una ternura (2011), de José Fernando Siale Djangany, y Matinga, sangre en la selva (2013), de Mbonio Bacheng, Lewis aborda la exploración de la dimensión mítica de Guinea Ecuatorial, junto a otros aspectos de su cultura. Los trabajos de estos autores tratan, sobre todo, de entender la complejidad que para su país supone la multiplicidad étnica y así, el colonialismo y la lucha por la independencia sirven como entrada para examinar cómo los guineanos perciben la transición y el impacto de estos acontecimientos sobre los modos de existencia tradicional.

No podía faltar, junto al colonialismo, el abordaje de la dictadura desde una perspectiva panafricanista, que analiza Lewis a partir de su análisis de Siete días en Bioko (2007), de Juan Manuel Davies, y Conspiración en el Green (El informe Abayak), de Francisco Zamora Loboch (2009). Ambos escritores, que llevan décadas fuera de Guinea y se formaron en Estados Unidos y España respectivamente, ofrecen

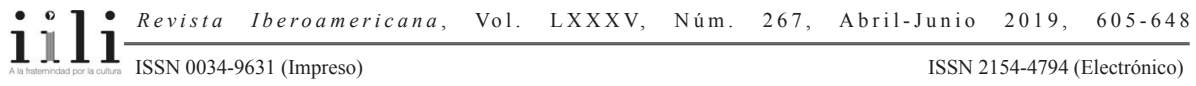


perspectivas del sistema político y económico de su país, el declinar de la tradición, la represión, junto a los movimientos de resistencia y revolución fuera de Guinea desde la independencia y la necesidad de cambio.

Otro tema que no podía estar ausente es la concepción de las lenguas tradicionales como una herramienta de resistencia cultural, sobre el que Lewis reflexiona a partir de su lectura de los poemarios de dos autores bubis y exiliados: Gerardo Behori Sipi Botau, con Sueños y realidad (2009), y Justo Bolekia Boleká, con Los callados anhelos de una vida (2012), en los que abordan temas como la memoria, la vivencia en un no-lugar, la identidad...

Y, por último, el capítulo siete se centra en la perspectiva de la gente, que trata desde el análisis de dos novelas de Juan Tomás Ávila Laurel: Avión de ricos, ladrón de cerdos (2008) y Arde el monte de noche (2009). Escritor disidente, crítico con las condiciones sociales y económicas de Guinea Ecuatorial y autoexiliado en Barcelona desde 2011, desde muy distintos géneros y escrituras, hasta el blog, llama al cambio en su país; así, en estas novelas, a través de interpretaciones culturalistas interroga sobre el legado colonial, la dictadura, las tensiones étnicas, la intervención occidental... con una perspectiva crítica consistente.

Como conclusiones, Lewis vuelve a reiterar la idea de que solo colocando a Guinea Ecuatorial en la perspectiva transnacional y transfronteriza podremos entender su literatura actual; al tiempo que hace una reflexión sobre el papel que debe ejercer esta: ante el fracaso de la independencia, las letras guineoecuatorianas deberían ser un arma para que la gente del país se apropie al fin, verdaderamente, de su fututo, lo que reconoce como difícil, mas no imposible.

En definitiva, Equatorial Guinean Literature in its National and Transnational Contexts, es una obra de lectura imprescindible para los que aman y para los que quieren empezar a acercarse a estas letras. Su gran aporte es, junto a la contextualización de esta literatura, hacernos caer en cuenta de la interesante paradoja que supone en sí misma esta expresión cultural en la actualidad. La experiencia transnacional de los guineanos (vidas diversas que se abren a nuevas y también dispares experiencias culturales) permite que un país con problemas conceptuales a nivel de nación -por su carácter multiétnico y porque estos grupos culturales apenas se han mirado entre sí-, apele a la reconciliación del país. Se trata de una literatura dis-locada, con autores que, desde la diáspora, con voces muy diferentes, pero todos africanos, a los que suman elementos de la modernidad y la globalización, y que escriben en español, hablan de reintegración en una nueva y moderna Guinea Ecuatorial.

Nayra Pérez Hernández

Universidad de Las Américas, Quito

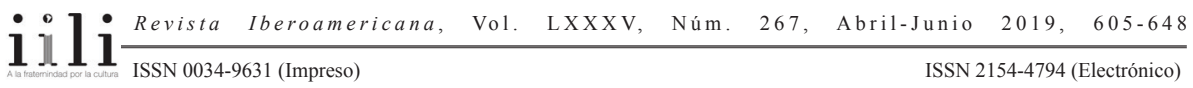

